\title{
Interpreting Maternal Death: When Underlying Causes Are Non-Medical Despite Medical Indications
}

\author{
Brahima A Diallo* \\ PhD Candidate, University of Bayreuth, Germany \\ Received: September 21, 2017; Published: October 03, 2017 \\ *Corresponding author: Brahima A Diallo, PhD Candidate, University of Bayreuth, Germany; Email: bradiallo@gmail.com
}

\section{Introduction}

The relationship between the medical caregiver and the patient usually displays an authoritative knowledge [1,2] of the former although the latter contributes to making the health care delivery more efficient [3]. Despite an involvement of the patient, his/her embodied knowledge [4] most often lacks legitimacy considering the health service delivery procedures particularly in the presence of a complication. However, the prominence of the patient's subjective interpretation may contribute to challenging the practice of the biomedicine regarding the accountability in some context. The following reflection draws on two cases of maternal death that occur in Ouenkoro's community health centre, a rural area in central Mali. The health facility is the first level of health care delivery in the Malian health systems. The midwife in charge of providing child birth services has been running the maternity for about thirty years. In the two cases highlighted the context of care delivery waschallenged by the parturient subjective interpretations of their conditions. Those accounts not only gained legitimacy over the clinical indications but also in reporting the maternal deaths from the perspective of the midwife.

\section{First Case}

Cisse did not show any sign of weakness in the last weeks into her pregnancy. She had been active, doing her routine household chores. When the water broke (labour), Cisse collected the items she would need after the birthing and headed to the maternity. Her elder sister accompanied her. In this rural setting, women mostly give birth at home, but Cisse did not delay resorting to the health centre. At the maternity, Cisse delivered her baby without complications. She even telephoned her husband and broke the news to him. Sadly, before her husband reached the health centre, Cisse passed away. After the birth of the baby, Cisse hada retained placenta. The midwife administered three injections of oxytocin and performed some manoeuvers, but these attempts were unsuccessful, she could not expel the placenta. The attendant noticed too vaginal discharge accompanied by blood clots. Moments later, the woman died. In fact, upon arrival at the maternity, Cisse told the mid wife that she knew she would not survive the child birth. Discussing with the mid wife,
Cisse told her that she consulted three different diviners, which all made a similar statement that she would experience complications in birthing that would result in her death.

Cisse faced the childbirth event with uncertainty, but the invading suspicion of death was over whelming. Confronted with the failure to help the parturient to deliver the placenta, the midwife started to lose hope mainly referring to a dream she had, weeks ago. The mid wife opines that she saw in a dream the death of a woman dressed in the type of cloth that she saw in the plastic bag of the parturient. She did not say anything to the parturient, but her faith in the dream seemed to get the upper hand over her medical skills. The midwife also reported remarks from passers by some days earlier who argued that they smelt the odour of a dead body in the maternity.

\section{Second Case}

A young primigravida was firstly taken to another primary health care centre in the area. She and the accompanying persons returned home following the notice from the medical care giver who informed them that it was not yet time for the pregnancy to be delivered. Preoccupied with the duration of the pregnancy but also the poor health state of the expectant mother, the same accompanying persons decided to resort to Ouenkoro's health care centre. Diagnosing the expectant mother, the midwife noticed that the labour already started, but the foetus was no more alive.

She expelled the stillborn baby, which was macerated. From the bad smell that suddenly engulfed the delivery ward, the midwife realized that the placenta was decayed. She tried to extract pieces of the placenta, but the cord remained blocked into the woman. She administered treatment to the parturient and left her under observation. Later on, the woman called the mid wife. The midwife arrived and asked the parturient about the part of her body that was in pain. The latter argued that she was fine but just wanted to thank her for her work. Noticing a weakness in the parturient, the midwife decided to put her on a drip. The woman objected to the idea of administering other medicines to her. She refused while arguing that drugs are just worthless because she already knew she 
would die. She rather requested to call on a Koranic scholar to make blessings for her. The accompanying persons managed to fulfill her wish before she passed away.

\section{Discussion}

From the midwife's account, both two cases resulted in maternal death, but any underlying medical causes were involved. The medical indications of retained placenta and bleeding from which maternal mortality ensued were allegedly perceived as secondary with regard to the parturient persuasion of her death and the dream she had. Performing deliveries, the progression of the stages of labor is supposed to be monitored with a partogramme. Through filling out the partogramme, the midwife should be able to detect any sign of obstetrical emergency to a woman in labor. Nevertheless, this tool (programme)was not usedin the two above deliveries. From scholars [5-7] not to resort to a partogramme while helping women at births in clinics appears to be a recurrent problem in some West African countries. Jaffré [5] notes, the partogrammesare deliberatelyignored because highlighting an anomaly or a mistake while attending to childbirth make to run the risk of revealing a fault for which one may be held responsible.

The discourse provided by the midwife draw on a premise of finding causes that are beyond the practice of the biomedicine, which negates any medical fault she may be held responsible. Furthermore, in a rural setting where (maternal) deaths are usually apprehended as fate, medical discourse on underlying causes are less convincing as compared with the metaphor "it happened because it ought to happen". This means, there is God's will behind everything. The subjective interpretations of the deceased mothers that were objectified afterward by the occurring of the events gained legitimacy over the health care delivery procedures, as the ways the midwife was supposed to deal with the childbirth.

Giving birth makes a mother more resilient [8]. She can rely on her embodied experience and make decisions that help her in birthing. However, bearing a child under certain circumstances as scarce economic conditions, the weight of household workload and the belief in external forces affect the resilience built through bodily experience, turn to hopelessness, and bring the woman to acquiesce certain complications she may experience in birthing as fate.

\section{Conclusion}

The provision of biomedicine services correlates with reutilized procedures that make it an objectified, grounded with a predefined or pre-coded relationship between the caregiver and the patient. The medical space in which the different interactions take place does not exempt actor's subjectivities. When the predefined procedures of care delivery are overlooked, this gives rise to subjective interpretations of the outcome of a medical practice to the detriment of the acknowledgment of a medical fault. The condition of existence in which the discourses are grounded perpetuates local universe of interpretation of the occurrence of realities as fate. Such an issue discussed in this study habitually interrogates laypersons' perceptions and representations about the practice of biomedicine. Interrogating the biomedicine provider rationality and his/her attempt at identifying external causes to medical outcomes bring about interesting perspectives regarding the practice of biomedicine but also the relationship between the professional and a layperson.

\section{References}

1. Jordan, Brigitte, Davis Floyd, Robbie (1993) Birth in four cultures: A cross cultural investigation of childbirth in Yucatan, Holland, Sweden, and the United States. Prospect Heights, Ill: Waveland Press, USA.

2. Jordan, Brigitte (1997) Authoritative knowledge and its construction. In Childbirth and Authoritative Knowledge: Cross-Cultural Perspectives, ed. Robbie Davis-Floyd and Carolyn Sergeant, Berkeley: University of California Press, USA, p. 55-79.

3. Wilde, Mary H (2003) Embodied knowledge in chronic illness and injury. Nursing Inquiry 10(3): 170-176.

4. Browner, Carole H, Press Nancy (1996) The Production of Authoritative Knowledge in American Prenatal Care. Medical Anthropology Quarterly 10(2): 141-156.

5. Jaffré, Yannick (2009) Anthropologie, Espaces Techniques de Soins et Réduction de la Mortalité Maternelle. In La Bataille des Femmes. Analyse anthropologique de la mortalité maternelle dans quelques services d'obstétrique d'Afrique de l'Ouest, ed. Yannick Jaffré, Yveline Diallo, Patricia Vasseur et Chrystelle Grenier-Torrès, France, p. 13-44.

6. Jaffré, Yannick (2012) Towards an anthropology of public health priorities. Maternal mortality in four obstetric emergency services in West Africa. Social Anthropology 20(1): 3-18.

7. Olivier de Sardan, Jean Pierre, Aïssa Diarra, Mahaman Moha (2017) Travelling models and the challenge of pragmatic contexts and practical norms: the case of maternal health. Health Research Policy and Systems 15(1): 71-87.

8. Lynn Clark Callister, Inaam Khalaf (2009) Culturally Diverse Women Giving Birth: Their Stories. In Childbirth across Cultures. Ideas and Practices of Pregnancy, Childbirth and the Postpartum, ed. Helaine Selin and Pamela K. Stone, New York, USA, p. 33-39.

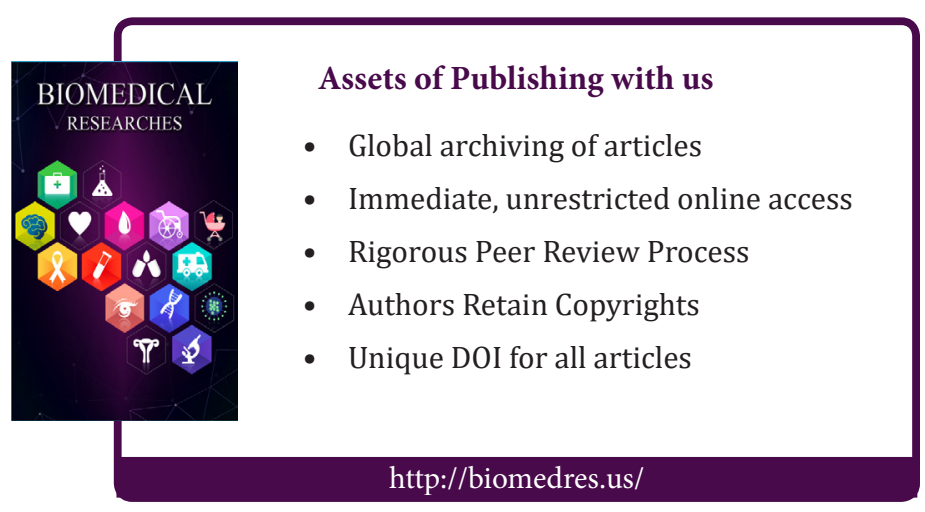

